\title{
GEOSTATISTICS IN GLACIOLOGY: IMPLICATIONS OF A STUDY OF SCHARFFENBERGBOTNEN, DRONNING MAUD LAND, EAST ANTARCTICA
}

by

U.C. Herzfeld

(Scripps Institution of Oceanography, Geological Research Division, A-015, University of California San Diego, La Jolla, CA 92093, U.S.A.)

and

P. Holmlund

(Naturgeografiska Institutionen vid Stockholms Universitet, S-10691 Stockholm, Sweden)

\section{ABSTRACT}

Geostatistical methods are applied in the analysis of radio-echo data from Scharffenbergbotnen, Dronning Maud Land, East Antarctica, in order to allow the following investigations: detailed and reliable cartography of subglacial bed topography and ice thickness, comparison of recent ice flow patterns and ice flow during earlier glacial maxima, and mass balance studies in relation to climatic changes.

\section{INTRODUCTION}

Scharffenbergbotnen (Figs 1, 2 and 3 ) is a glaciated valley in north-west Sivorgf jella, Heimef rontf jella $\left(74^{\circ} 35^{\prime} \mathrm{S}\right.$, $11^{\circ} 40^{\prime} \mathrm{W}$ ) with an inflow from the surrounding inland ice, but a flux in the opposite direction to the surrounding ice. The valley trends west-north-west to east-south-east across the orientation of the Heimefrontfjella mountain range (Spaeth and Fielitz, 1987). The range builds an obstruction to the general north-westward inland ice flow.

The glacier was surveyed with a radio-echo sounding equipment in the glaciological part of the Swedish Antarctic Program (SWEDARP) during the German Antarctic Expedition VI/3 1987/88 (Alfred-Wegener-Institut für Polarund Meeresforschung, Bremerhaven, Federal Republic of Germany) (Jonsson and others, 1988). The glacier surface data are taken from a manuscript map, scale $1: 25000$, provided by the Institute of Applied Geodesy (IFAG), Frankfurt, Federal Republic of Germany (1986). The

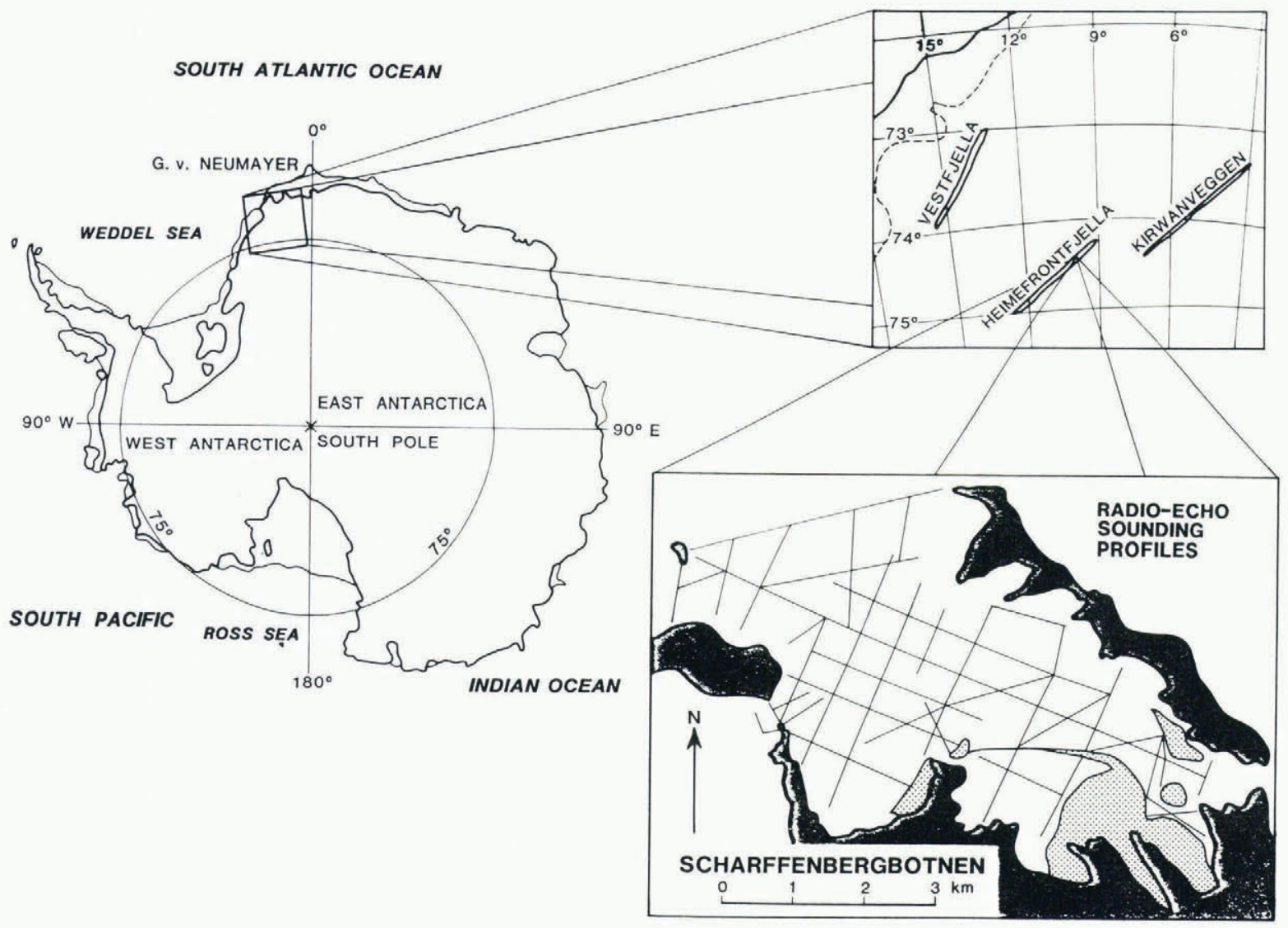

Fig. 1. Location of Scharffenbergbotnen, Heimefrontf jella, Dronning Maud Land, East Antarctica. The inset maps show the location of Heimefrontfjella and of the radio-echo survey tracks on Scharffenbergbotnen glacier. 


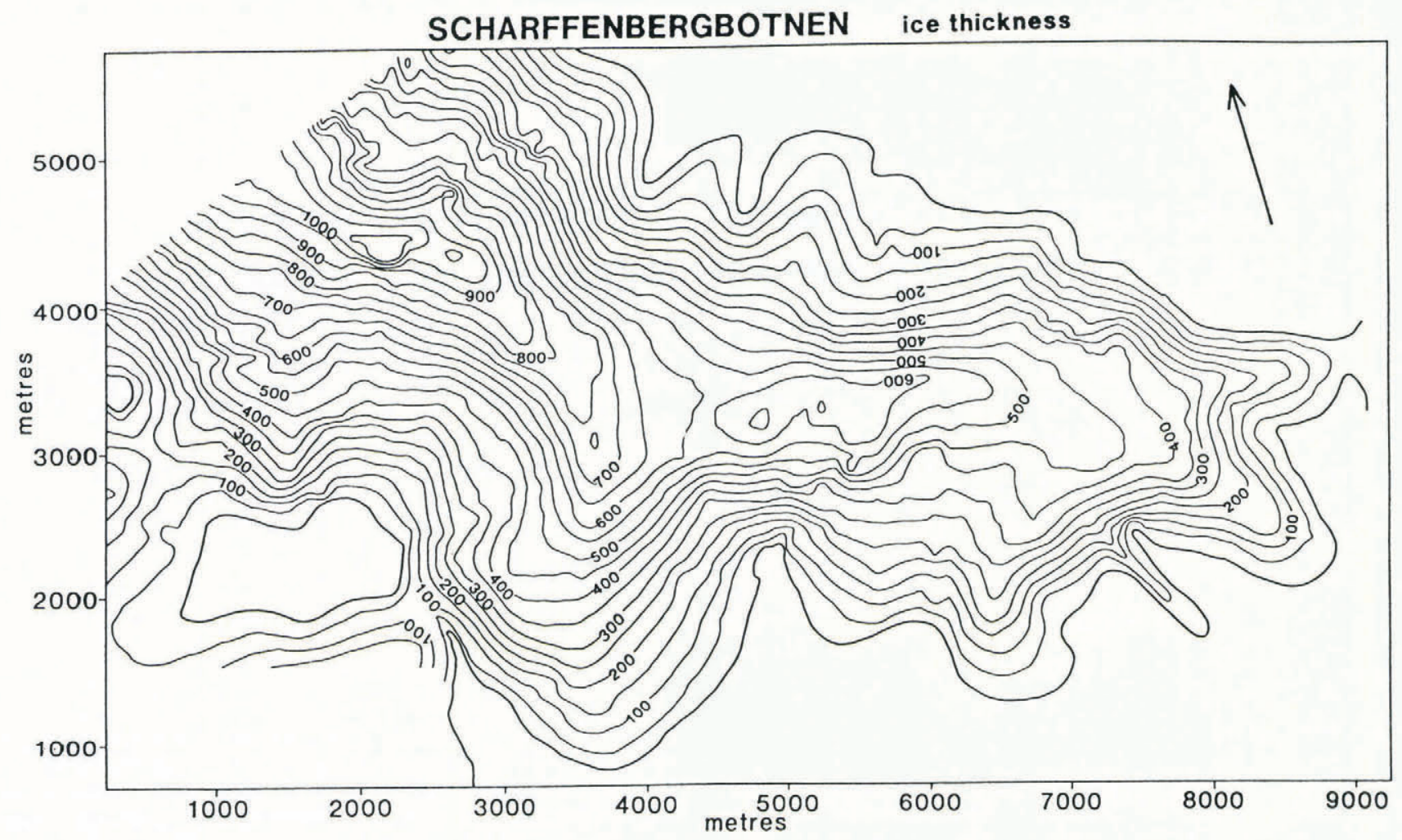

Fig. 2. Ice thickness in Scharffenbergbotnen basin, contoured from a DTM based on universal kriging of radio-echo soundings, using a spherical variogram with parameters nugget effect $=2000 \mathrm{~m}^{2}$, sill $=$ $78000 \mathrm{~m}^{2}$, range $=2500 \mathrm{~m}$ (see Fig. 5).

distribution of the radio-echo data follows continuous sampling profiles of varying orientation, giving a situation of dense information along the profiles and gaps in between (Fig. 1). Because this distribution does not permit immediate isoline interpolation, the geostatistical method of universal kriging is used to estimate values in the survey gaps between the profiles.

\section{GEOSTATISTICAL EVALUATION METHOD}

Geostatistics is understood as the theory of regionalized variables in the sense of Matheron (1963). Kriging has optimal properties as it yields minimal estimation errors, unbiased estimation, and a description of the estimation error without additional computation effort (for general reference, see Journel and Huijbregts (1978)).

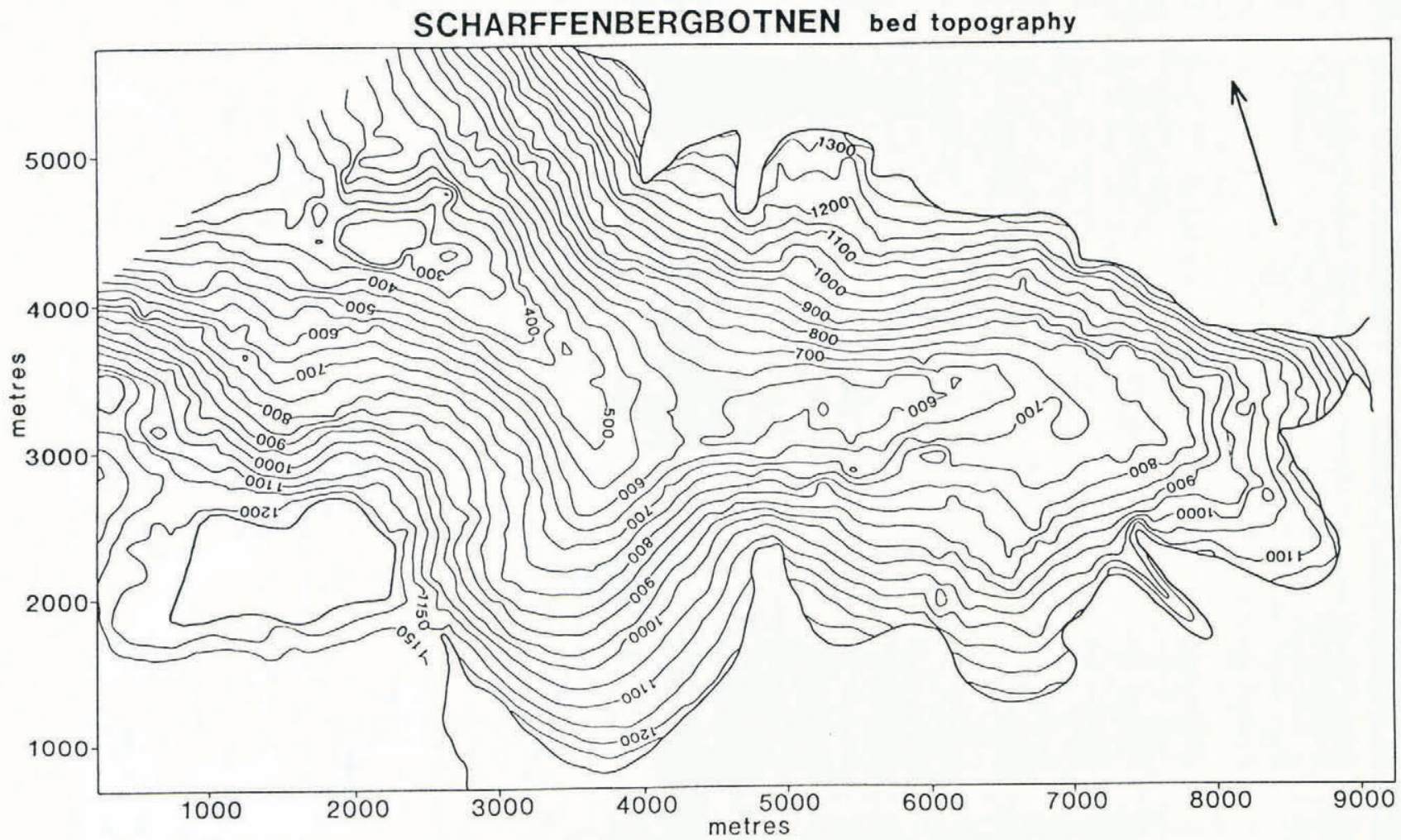

Fig. 3. Subglacial bed topography of Scharffenbergbotnen basin, contoured from a DTM based on universal kriging of radio-echo soundings, using a Gaussian variogram with parameters nugget effect $=2000 \mathrm{~m}^{2}$, sill $=105000 \mathrm{~m}^{2}$, range $=2200 \mathrm{~m}$ (see (a) in Fig. 6). 


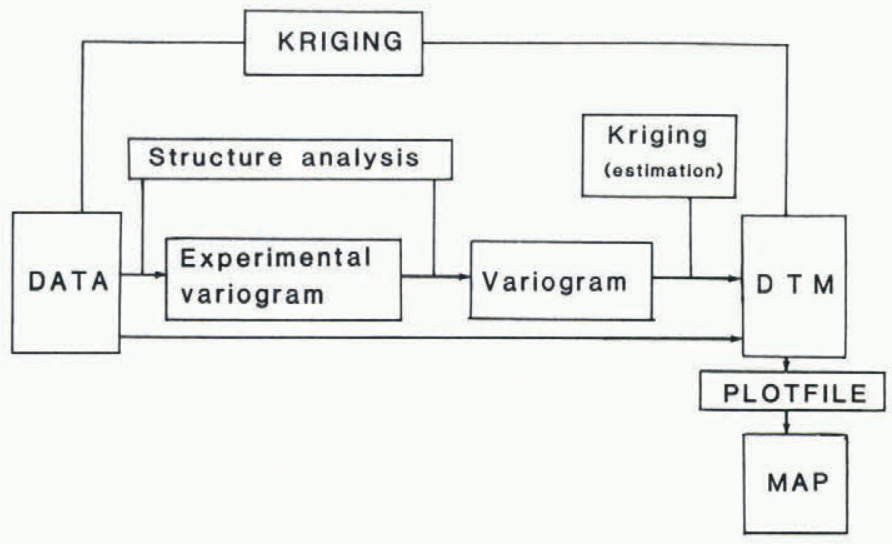

Fig. 4. Diagram of the kriging procedure.

The kriging method comprises several steps (Fig. 4). The goal is to build up a digital terrain model (DTM), defined by a regular grid and an algorithm. The gridded data can be contoured. Ice thickness and subglacial bed elevation are considered regionalized variables in the following sense: measurements taken in neighbouring locations show a high covariation, in addition the data bear an overall random variation. In the first kriging step, this spatial continuity of the data is analysed and modeled by a function called variogram. The variogram is characterized by its type (that has to satisfy certain mathematical conditions) and the parameters "nugget effect", "sill", and "range" (Fig. 5). In practice, the range indicates the maximal distance between two observations that can be interpolated by kriging. The sill is the total variance of data further apart than the range, and the nugget effect represents the residual variance of repeated measurements at the same location.

In the Scharffenbergbotnen study, global and directional variograms were calculated from the total data set. The ice thickness variogram is modeled by a spherical function as shown in Figure 5. For subglacial bed topography, the Gaussian variogram model (line (a) in Figure 6) is preferred to the linear model (line (b) in Figure 6). The results of the variography are necessary to solve the kriging equations. In addition, the variography provides parametric information of glaciological relevance, that is valuable particularly in an early stage of the investigation. For instance, the derivative of the variogram at the origin gives the degree of mean square differentiability of the regionalized variable, which in the latter case relates to the roughness of the subglacial surface. It follows that subglacial topography is (in the

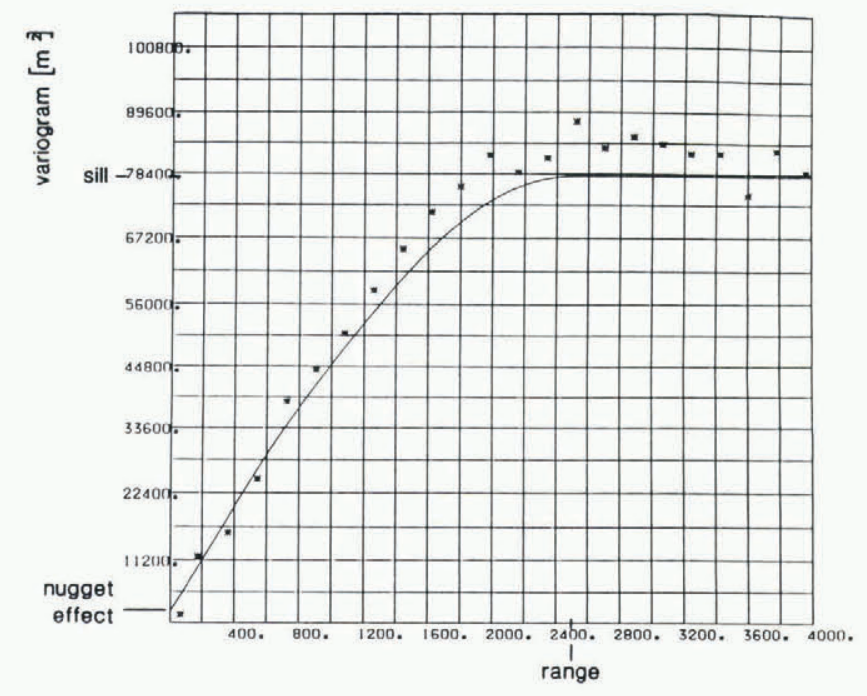

distance $[\mathrm{m}]$

Fig. 5. Variogram of Scharffenbergbotnen ice thickness, *, experimental variogram; -, spherical variogram model with parameters nugget effect $=2000 \mathrm{~m}^{2}$, sill $=78000 \mathrm{~m}^{2}$, range $=2500 \mathrm{~m}$.

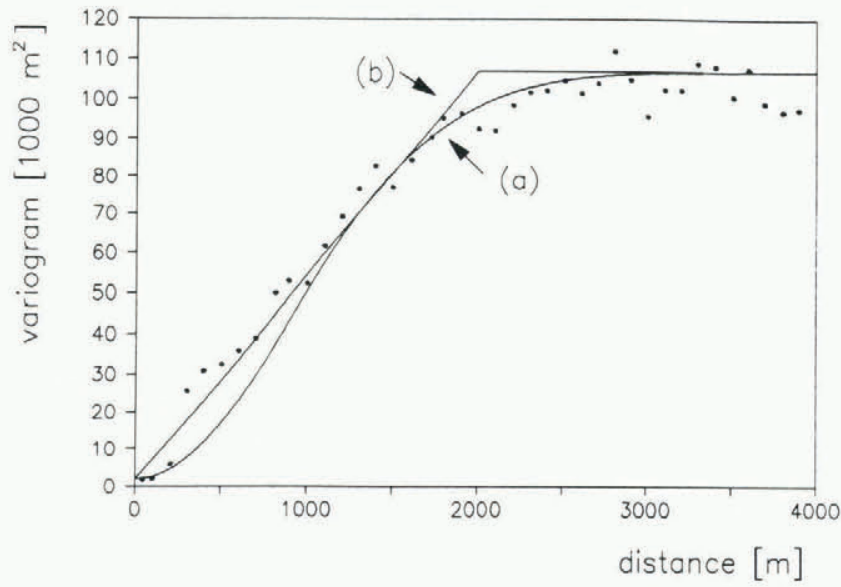

Fig. 6. Variogram of Scharffenbergbotnen subglacial bed topography. *, experimental variogram; a, Gaussian variogram with parameters nugget effect $=2000 \mathrm{~m}^{2}$, sill $=$ $105000 \mathrm{~m}^{2}$, range $=2200 \mathrm{~m} ; \mathrm{b}$, linear variogram with sill, with parameters nugget effect $=2000 \mathrm{~m}^{2}$, sill $=$ $105000 \mathrm{~m}^{2}$, range $=2200 \mathrm{~m}$. The Gaussian model is preferred because of its better fit, in particular near the origin.

mean-square sense) smoother than ice thickness. An example of geological interpretation of parametric changes of directional variograms is given in Herzfeld and Holmlund (1988).

In the second step, the DTM is constructed using the following estimation procedure at every grid node: The value $z\left(x_{\mathrm{p}}, y_{\mathrm{p}}\right)$ at a node $\left(x_{\mathrm{p}}, y_{\mathrm{p}}\right)$ is predicted using the kriging estimator

$$
Z^{*}=\sum_{i=1}^{n} a_{\mathrm{i}} Z_{\mathrm{i}}
$$

where $Z_{i}=z\left(x_{i}, y_{i}\right), i=1, \ldots, n$, are data measured in points $\left(x_{i}, y_{i}\right)$ in a neighbourhood of the node $\left(x_{\mathrm{p}}, y_{\mathrm{p}}\right)$, and $a_{i}$ are real coefficients. The coefficients are determined such that the estimation variance is minimal (here the variogram is used).

However, ice thickness and subglacial bed elevation are non-stationary variables that bear a characteristic trend (to give a simple example, ice thickness increases towards the center of the glacier). The non-stationarity is taken into account by solving the minimization problem with respect to appropriate unbiasedness conditions, using a universal kriging estimator. A more elaborate description of data acquisition and evaluation methods is given in Herzfeld and Holmlund (1988), for the software used see Herzfeld (1989?).

\section{RESULTS}

The resultant large scaled maps $(1: 20000)$ of Scharffenbergbotnen ice thickness (Fig. 2) and subglacial bed topography (Fig. 3) have a high precision and reliability. Although the grid spacing is finer $(100 \mathrm{~m}$ by $100 \mathrm{~m})$ than the profiling (c. $500 \mathrm{~m}$, see Fig. 1), survey patterns cannot be recovered from the contoured values. Absolute estimation standard deviation is less than $5 \mathrm{~m}$ throughout, while maximal ice thickness is $1050 \mathrm{~m}$. Their accuracy qualifies the maps as a basis for further investigations of ice flow, glacier dynamics, and mass balance.

The maps reveal morphological structures and ice-flow patterns that were not detectable in the field data using non-mathematical evaluation. A shallow ridge can be observed in the central part of the valley. Just upstream of the ridge the glacier branches off southwards with only a part continuing in the main north-east to south-western direction. It is possible to conclude the existence of a shallow overdeepening and of traces of an earlier inflow from the south, which are regarded as remnants of a former erosive, warm based glacier. 


\section{ACKNOWLEDGEMENTS}

The work presented in this paper was carried out during the German Antarctic Expedition VI/3 1987/88, Alfred-Wegener-Institut für Polar- und Meeresforschung, Bremerhaven, Federal Republic of Germany. The field surveys were part of the Swedish Antarctic Research Program (SWEDARP), while the data evaluation was performed on the VAX $11 / 750$ shipboard computer of FS Polarstern. Thanks are due to Dr S. Jonsson who lead the glaciological project, to $\mathrm{H}$. Grudd for his assistance in the field work, to $\mathrm{H}$. Klindt for help with the data transfer, to J. Jacobs for unpublished information on tectonical measurements, and to the members of Tarfala Research Station, northern Sweden (University of Stockholm) for their hospitality during further evaluations in July 1988. In sof tware development, geostatistics programs from the Free University of Berlin Institute of Geology (Mathematical Geology) were used. Here we are indebted to Prof. Dr W. Skala, Dr H. Burger, and Dr R. Schoele. Symposium participation (U.C.H.) was made possible by special support from the Alexander von Humbolt Foundation, Bonn.

\section{REFERENCES}

Herzfeld, U.C. 1989?. Geostatistical software for evaluation of line survey data, applied to radio-echo soundings in glaciology. In Hanley, J.T. and D.F. Merriam, eds. Microcomputer applications in geology. II. Oxford, Pergamon Press, 113-136.

Herzfeld, U.C. and P. Holmlund. 1988. Geostatistical analyses of radio-echo data from Scharffenbergbotnen, Dronning Maud Land, East Antarctica. Z. Gletscherkd. Glazialgeol., 24(2).

Jonsson, S., P. Holmlund, and H. Grudd. 1988. Glaciological and geomorphological studies of Scharffenbergbotnen. Ber. Polarforsch. 58, 186-193.

Journel, A. and C. Huijbregts. 1978. Mining geostatistics. London, Academic Press.

Matheron, G. 1963. Principles of geostatistics. Econ. Geol., $58,1246-1266$.

Spaeth, G. and W. Fielitz. 1987. Structural investigations in the Precambrian of western Neuschwabenland, Antarctica. Polarforschung, 57(1/2), 71-92. 